\title{
An Evaluation and Dissemination Model for the Machine Learning Embedded System Lifecycle in Clinical Practice Settings
}

\author{
melanie besculides ${ }^{1}$, Ksenia Gorbenko ${ }^{1}$, Cardinale Smith ${ }^{1}$, Robert Freeman ${ }^{1}$, David Reich ${ }^{1}$, \\ Arash Kia ${ }^{1}$, and Madhu Mazumdar ${ }^{1}$ \\ ${ }^{1}$ Mount Sinai School of Medicine
}

June 25, 2021

\begin{abstract}
Machine learning (ML) algorithms are gaining popularity in clinical practice settings due to their ability to process information in ways that augment human reasoning. While tools that rely on output from ML algorithms in the healthcare setting are appealing for their ability to aid in clinical decision making and streamline workflows, their implementation and effectiveness are not well documented. There is an abundance of published ML literature that focuses on whether algorithms can predict an outcome or predict it better than previous algorithms, but a dearth of effort evaluating their implementation or impact on patient outcomes. While developing and validating algorithms is an important first step in research, comprehensive evaluation is needed before application of ML algorithms in new settings is considered. Evaluation should examine both the process of implementation and the outcomes using a mix of qualitative and quantitative methods. This commentary describes a model we developed to guide our institutional ML evaluation efforts.
\end{abstract}

\section{Hosted file}

MLEvalCommentary_061021.docx available at https://authorea.com/users/421975/articles/527799an-evaluation-and-dissemination-model-for-the-machine-learning-embedded-system-

lifecycle-in-clinical-practice-settings

\section{Hosted file}

Table 1_061021.docx available at https://authorea.com/users/421975/articles/527799-anevaluation-and-dissemination-model-for-the-machine-learning-embedded-system-lifecyclein-clinical-practice-settings 
Figure 1. Machine Learning Embedded System Lifecycle, Evaluation and Dissemination

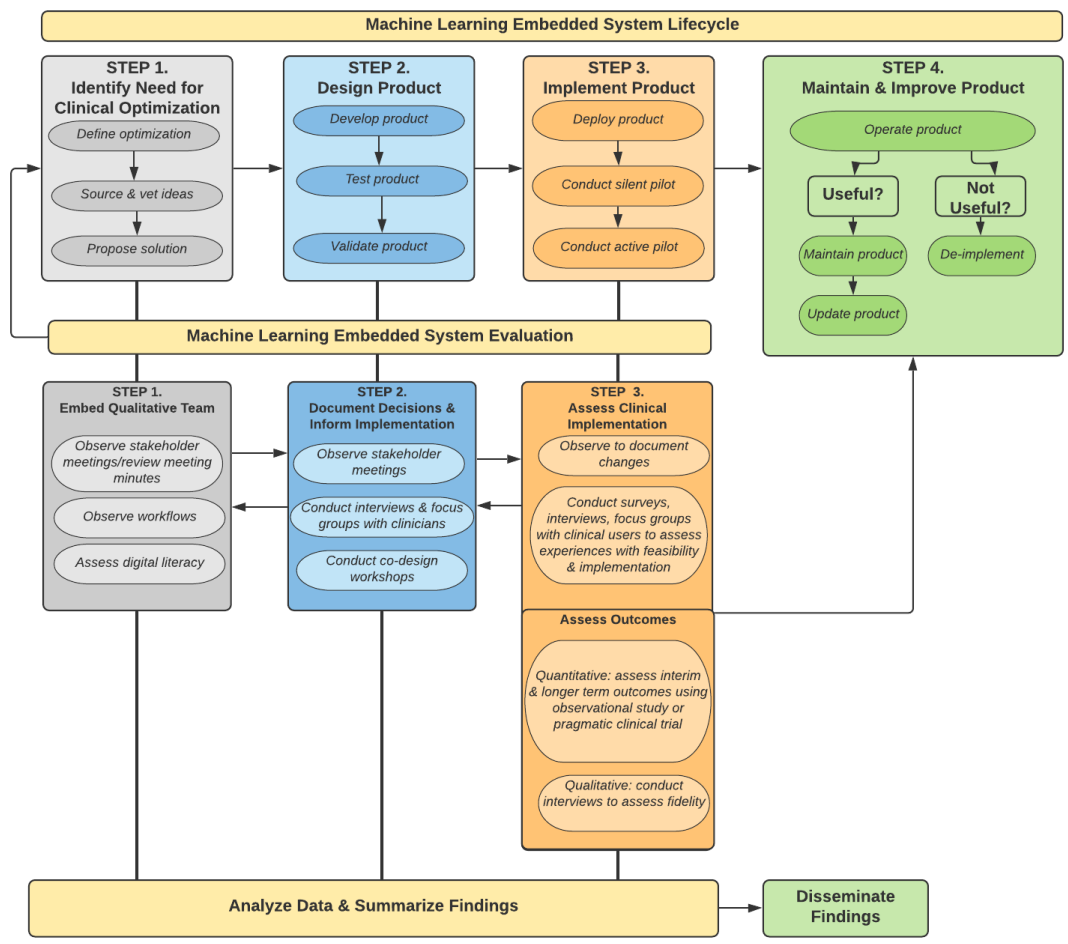

